\title{
Indirect Cold Atmospheric Pressure Plasma treatment on Melanoma and Fibroblast Cells
}

\author{
Pei-Ru Chen ${ }^{1}$, Yun-Ju Chuang 1* (D) \\ 1 Department of Biomedical Engineering, Ming Chuan University, Taiwan, R.O.C \\ * Correspondence: yjchuang@ mail.mcu.edu.tw;
}

Scopus Author ID 7202686959

Received: 15.09.2020; Revised: 15.10.2020; Accepted: 17.10.2020; Published: 21.10.2020

\begin{abstract}
Cold atmosphere plasma has been shown as a promising technology for certain cancer treatments. In this paper, we report indirect plasma treatment using CAP discharged in cell culture medium and study the effect of identical plasma stimulated culture medium on melanoma cancer cells and fibroblast cells cultured in vitro. The results of MTT assay, migration assay, ROS detection, and alizarin red assay show that plasma-treated medium can have a strong negative effect on melanoma cancer cells compared with the control group. However, the plasma-treated medium has a less cytotoxic effect on fibroblast cells than that on melanoma cancer cells at the same treatment. This result is attributed to the production of reactive oxygen species in the plasma-treated medium to induce apoptosis and inhibit melanoma cell proliferation and further cell metastasis. According to the results, this study shows the potential of CAP plasma treatment for anti-cancer therapy.
\end{abstract}

Keywords: cold atmospheric plasma; non-invasive treatment; melanoma cell.

(C) 2020 by the authors. This article is an open-access article distributed under the terms and conditions of the Creative Commons Attribution (CC BY) license (https://creativecommons.org/licenses/by/4.0/).

\section{Introduction}

Melanoma is the deadliest form of skin cancer. According to the data from the World Health Organization, there are more than 132,000 new cases of malignant melanoma are diagnosed each year globally [1]. The eradication of cancer cells through apoptotic processes are the common goal of anti-cancer therapies [2]. However, melanoma cells show high resistance to chemotherapeutic agents and have lower apoptosis rates as compared with other tumor cells due to the high mutation rate of metastatic melanoma [3-5].

Caspase cascades are the central elements in cell apoptosis progression. Besides caspase-dependent apoptosis, there are several types of a research report that the existence of caspase-independent cell apoptosis pathways [6]. In caspase-independent pathways, reactive oxygen species (ROS) have been studied to promote apoptosis due to its capability of inducing loss of mitochondrial membrane potential causing mitochondrial damage and subsequent release of apoptotic factors [7]. ROS can also activate the c-Jun N-terminal kinases (JNKs) signaling pathway, induce melanoma apoptosis through caspase-independent pathways [2]. Therefore, some therapies reported the utilization of ROS as an effective way to cause cancer cell death [8].

Plasma is a partially ionized gas composed of ions, electrons, photons, and neutral species, including radicals, molecules, and exciting species. Plasma is generated by applying an energy source to a neutral gas, causing ionization or dissociations due to interactions between electrons and ions, and a mixture of reactive species will be generated in the plasma 
[9-11]. Plasma can be characterized into two different types, thermal and non-thermal plasma, according to the electrons, are in thermal equilibrium with ions or not. In the non-thermal plasma, cold atmospheric pressure plasmas (CAPs) have attracted a lot of attention in biomedical applications due to the possibility to operate in an atmosphere environment without a vacuum system and to treat living cells or heat-sensitive tissues. Operated with ambient air, CAP contains reactive nitrogen/oxygen species (RNS/ROS) such as nitric oxide (NO), nitrogen dioxide $\left(\mathrm{NO}_{2}\right)$, ozone $\left(\mathrm{O}_{3}\right)$, superoxide $\left(\mathrm{O}_{2}^{-}\right)$and hydroxyl radicals $\left({ }^{-} \mathrm{OH}\right)$ [10].

It is well known that ROS and RNS are able to induce cell apoptosis and damage proteins, lipids, and DNA and consequently lead to cell death [12,13]. Recently, many research suggested that the application of CAP as an innovative approach for cancer treatment and had successfully decreased cancer cell growth in vitro and tumor burden in vivo on cancer therapy applications, including breast cancer [13], lung carcinoma [14-16], hepatocellular carcinoma [17], neuroblastoma [18], skin carcinoma [19], melanoma [20], colon carcinoma [21], pancreatic carcinoma [22], bladder carcinoma [14], and cervical carcinoma [23, 24]. In most reported studies, CAP was used directly to irradiate cancer cells or tissues. However, direct CAP jet irradiation can only cause cell death in the upper three to five cell layers, and its application is limited [25]. In this study, a new CAP device was designed to generate RONS in DI, and studied its effects on melanoma B16 and fibroblast L929 cells in vitro. We aim to explore the effects and possible mechanism of identical plasma treatment time durations on cancer cells and normal cells.

\section{Materials and Methods}

\subsection{CAP plasma device.}

The schematic setup of the cold atmospheric pressure plasma jet device used in this paper is shown in Figure.1. The cold atmosphere plasma jet device was made in the lab, and it consists of a quartz tube ( $9 \mathrm{~mm}$ in diameter) with one inner and one outer electrode. The hollow quartz tube is used as a dielectric insulator between inner and outer electrodes. Helium gas is used as a working gas at atmospheric pressure, and the volume flow rate is controlled by using a mass flow rate controller. The flow rate of helium gas is set to be $41 \cdot \mathrm{min}-1$. A radio frequency power supply with a frequency of $13.56 \mathrm{MHz}$ and a power of $4 \mathrm{~W}$ is applied to the two electrodes of CAP jet device.

Optical emission spectroscopy (OES) is used to assess various species in CAP plasma. Here, OES results are shown as qualitative analysis but not quantitative results. In this work, a wavelength of 200 to $1000 \mathrm{~nm}$ was investigated to detect various atmospheric plasma species, including atomic oxygen [O], hydroxyl radical [OH-], nitrogen [N2], and helium [He]. Optical emission spectroscopy (OES) consists of a collimating lens, an optical fiber probe, and an optical emission spectrometer (Ocean optics QE65000). The optical probe is placed $2 \mathrm{~cm}$ in front of the plasma jet nozzle.

\subsection{Cell line and cell culture.}

The murine melanoma cell line B16 and fibroblast cell line L929 are purchased from the Culture Collection and Research Center (Hsinchu, Taiwan). The B16 and L929 cells are cultured in fresh DMEM culture medium and incubated at $37^{\circ} \mathrm{C}$ in a humid atmosphere containing 5\% CO2. The culture medium is composed of DMEM (Sigma-Aldrich, USA) containing $10 \%$ fetal bovine serum (FBS, Sigma-Aldrich, USA), $100 \mathrm{U} \cdot \mathrm{ml}-1$ penicillin, and 
$0.1 \mathrm{mg} \cdot \mathrm{ml}$ streptomycins. The culture medium is changed every two days until the cells reach 90\% confluence. Prior to plasma treatments, the B16 and L929 cells were washed with phosphate-buffered saline solution and seeded in 24 wells plate with the desired concentration.

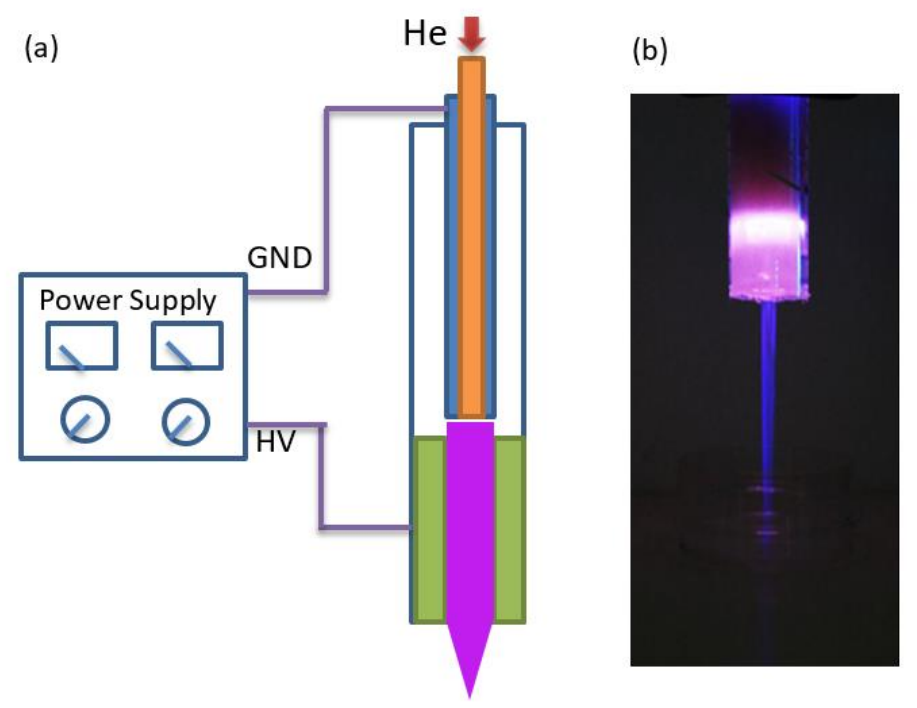

Figure 1. (a) Schematic setup of CAP device. (b) Images of He plasma generated by CAP device.

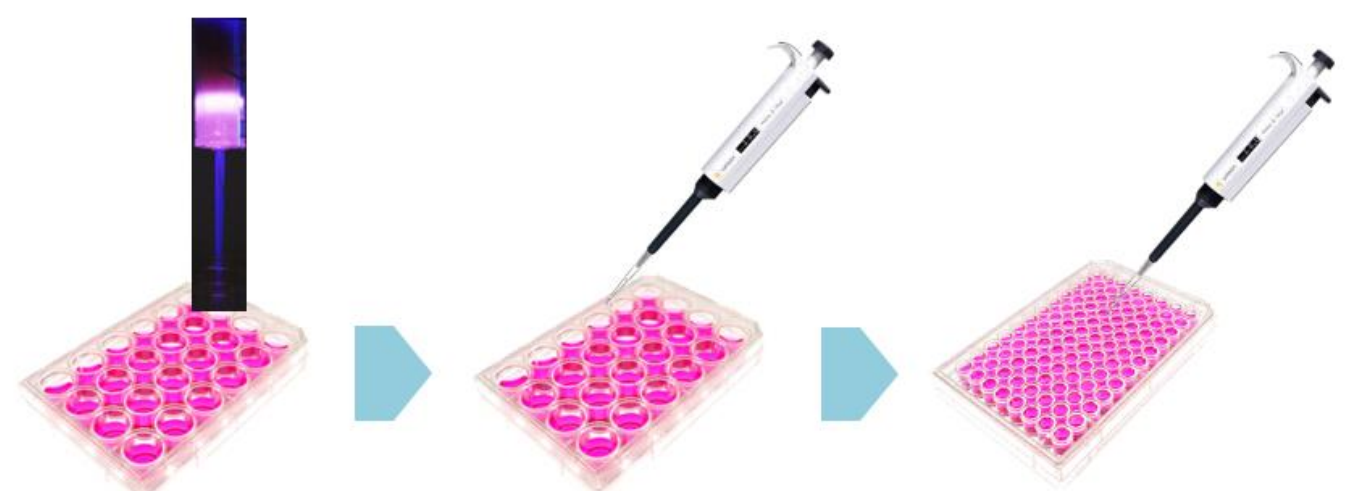

Figure 2. Representation of the indirect plasma treatment stages. First, CAP vertically irradiates the culture medium in different wells of a 24-well microplate. Then, the treated medium was transferred for the different wells of a 96-well microplate, in which the cells were previously cultured.

\subsection{Plasma treatments.}

The indirect cold atmospheric pressure plasma treatment was performed using CAP jet device to vertically irradiate the culture medium in wells of 24 well plate, and then the plasmatreated medium was transferred to the cultured B16 and L929 cells. Before the transfer step, the cell culture medium was drawn out, and the cells were washed with fresh PBS buffer solution. After that, the plasma-treated culture medium was immediately transferred to 96 well cell culture plates, and the cells were incubated under standard culture conditions (see Figure. 2). Cells cultured with an untreated medium was used as a positive control in experiments.

\subsection{MTT cell viability assay.}

Cell viability was evaluated by using MTT (3-(4, 5-dimethylthiazol-2-yl)-2, 5diphenyltetrazolium bromide) assay (Sigma-Aldrich M2128), a colorimetric assay for detecting the activity of cell mitochondria. A $200 \mu \mathrm{l}$ MTT solution was added into each well 
in 96 well plates, and then cells were incubated for $3 \mathrm{~h}$ in the dark under standard conditions. After incubation, a medium containing MTT was discarded, and $200 \mu \mathrm{l}$ dimethyl sulfoxide (DMSO) solution was added into wells to dissolve insoluble purple formazan product into a colored solution. This colored solution was measured spectrophotometrically at $570 \mathrm{~nm}$ by using a microplate reader.

\subsection{Cell migration assays.}

Migration assays were performed by seeding 10000 B16 and L929 cells in 24 well plates and cultivated with $1 \mathrm{ml}$ DMEM contains $10 \% \mathrm{FBS}$ in $37{ }^{\circ} \mathrm{C}$ incubator for $24 \mathrm{~h}$. Then one artificial wound per well is scratched into the cell monolayers with a sterile plastic 1000 $\mu \mathrm{l}$ micropipette tip resulting in a $900 \mu \mathrm{m}$ gap in the monolayer. The migration of cells and closure of the gap were observed and recorded by microscope after cell incubation with a plasma-treated culture medium. The recorded images were used for the analysis of the cell gap closure area ratio by Image $\mathbf{J}$ software.

\subsection{Intracellular ROS detection.}

The DCFH-DA assay kit was used to detect the intracellular reactive oxygen species (ROS) after cell incubation with a plasma-treated medium. After seeding 10000 B16 and L929 cells in 24 well plates and being cultivated with $1 \mathrm{ml}$ DMEM contains $10 \% \mathrm{FBS}$ in $37^{\circ} \mathrm{C}$ incubator for $24 \mathrm{~h}, 10 \mathrm{mM}$ dichlorofluorescein diacetate (DCFH-DA) was added into the well, and the cells were incubated at $37^{\circ} \mathrm{C}$ in a humid atmosphere containing $5 \% \mathrm{CO}_{2}$ for $30 \mathrm{~min}$. The 2', 7'- dichlorodihydrofluorescein diacetate reacted with reactive oxygen species to form fluorescent 2', 7'-dichlorofluorescin (DCF). When the incubation was finished, the cells were washed with a phosphate-buffered solution 2 times. Fluorescence images are obtained by the fluorescence microscope at an excitation wavelength of $488 \mathrm{~nm}$ and an emission wavelength of $515 \mathrm{~nm}$. The green fluorescence indicated the existence and concentration level of intracellular ROS.

\subsection{Alizarin red assay.}

The Alizarin red assay was used to determine, quantitatively by colorimetry, the presence of calcific deposition by cells. The intracellular or extracellular calcific deposition both indicated the death of cells. The operation procedure was as follows. The $10000 \mathrm{~B} 16$ and L929 cells were seeded in 24 well plates and cultivated with a plasma-treated medium for 24 h. The culture medium was discarded, and the cells were washed gently three times with PBS solution. After fixing the cells with $4 \%$ formaldehyde for $15 \mathrm{~min}$ at room temperature and washing the cells two times with PBS solution, $1 \mathrm{ml}$ of $40 \mathrm{mM}$ ARS was added into each well, and the cells were incubated for $30 \mathrm{~min}$ at room temperature. When the incubation was finished, the cells were washed three times with deionized water to remove ARS dye and then observed with a microscope.

\section{Results and Discussion}

To investigate the species generated by the cold atmosphere plasma, the emission gas of the plasma jet was characterized. Figure. 3 shows the optical emission spectrum of He plasma discharge in the wavelength range from 200 to $1000 \mathrm{~nm}$ obtained with a gas flow rate of $4 \mathrm{slm}$ and in $2 \mathrm{~cm}$ distance outside the jet nozzle. Based on the analysis of the obtained 
emission spectrum, the identified emission peak, including $\mathrm{N}_{2}, \mathrm{~N}_{2}+\mathrm{He}$, and reactive radicals like $\mathrm{OH}$ and $\mathrm{O}$, can be observed. From the emission spectrum, $\mathrm{OH}$ peaks can be found at 297, and $309 \mathrm{~nm}$, lines in the range of 600 to $800 \mathrm{~nm}$ are He gas, peaks at 337 and $358 \mathrm{~nm}$ are the result of the formation of $\mathrm{N} 2$ second-positive system generated through an inelastic collision between electrons and nitrogen and $\mathrm{N} 2+$ negative system mainly comes from the Penning ionization between excited $\mathrm{He}$ and nitrogen. And, $\mathrm{O}$ and $\mathrm{OH}$ radicals are also identified as a result of the existence of oxygen and water vapor in the atmosphere.

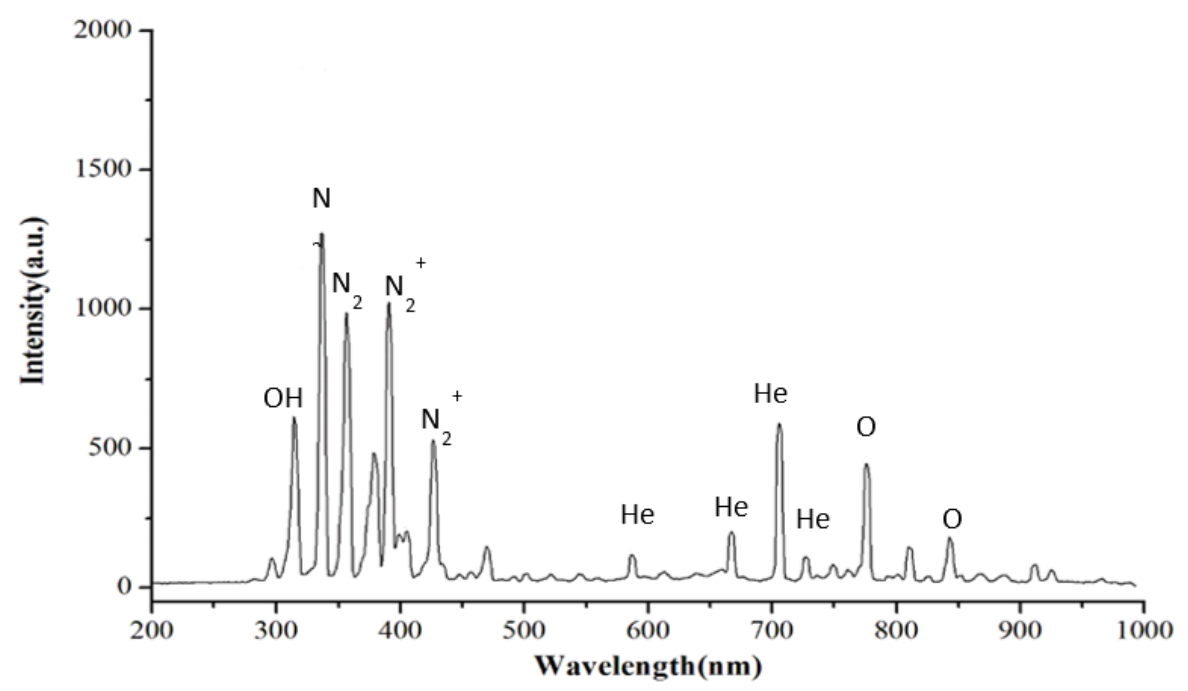

Figure 3. Optical Emission Spectrum of CAP plasma.

In order to compare the effect of plasma-treated medium on the B16 and L929 cells, cell viability was detected under the same parameters as a function of treatment time. The MTT assay assesses cell metabolic activity, which reduces tetrazolium dye MTT to insoluble formazan. The OD value represents the degree of resulting formazan concentration accumulated in cells; the greater the formazan concentration, the more living cells. The OD value is normalized to be 1 for each control group. From Figure. 4 , it can be seen that the viability of B16 cells is reduced with increasing plasma treatment time from $60 \mathrm{sec}$ to $360 \mathrm{sec}$ compared to the control group. With increasing incubation time to 7 days, the OD value of B16 cells decreases significantly. The OD value does not change significantly compared with the control group when the treatment time is less than $60 \mathrm{sec}$. And the OD value decreases significantly with treatment time ranging from 180 to $360 \mathrm{sec}$. A similar response to plasma treatment can be found in L929 cells. For L929 cells, the OD values do not change significantly compared with the control group with treatment time less than $60 \mathrm{sec}$. And the OD value decreases with plasma treatment time longer than $180 \mathrm{sec}$. The viability rate of L929 cells does not decrease significantly with plasma treatment time as compared with B16 cells. It is observed that the L929 cells show no significant viability change under 7 days incubation. However, the viability of B16 cells decreases rapidly with plasma treatment time longer than $180 \mathrm{sec}$ after 7 days of incubation. These data show that the negative impact in cellular response is more significant on B16 cells than on L929 cells. And this indicates that CAP plasma treatment does not have a harmful effect on normal cells/tissues but does have an obviously suppressed effect on cancer cell proliferation. Furthermore, the morphologies of the cells with plasma treatment are observed, and the images are shown in Figure. 5. From these images, we can find that the attached cells of B16 decrease rapidly as the plasma treatment time increases as compared with the control group. However, the L929 cells show no significant change until 
the plasma treatment time reaches $180 \mathrm{sec}$. Cell viability data and morphology images both show that the B16 cells are more sensitive than L929 cells under the CAP plasma treatment.

day1

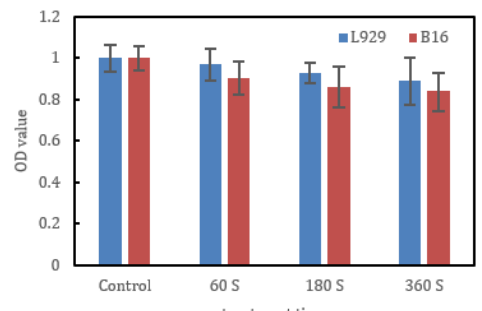

day 3

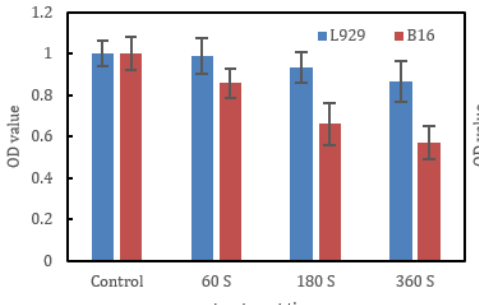

day 7

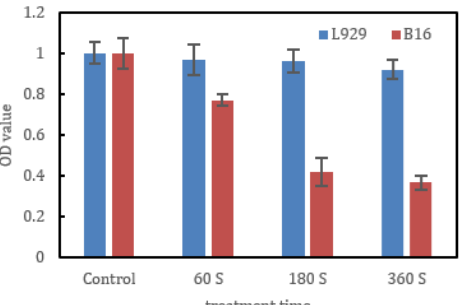

Figure 4. Effect of CAP plasma treatment time on cell viability analyzed 1, 3, and 7 days after treatment.
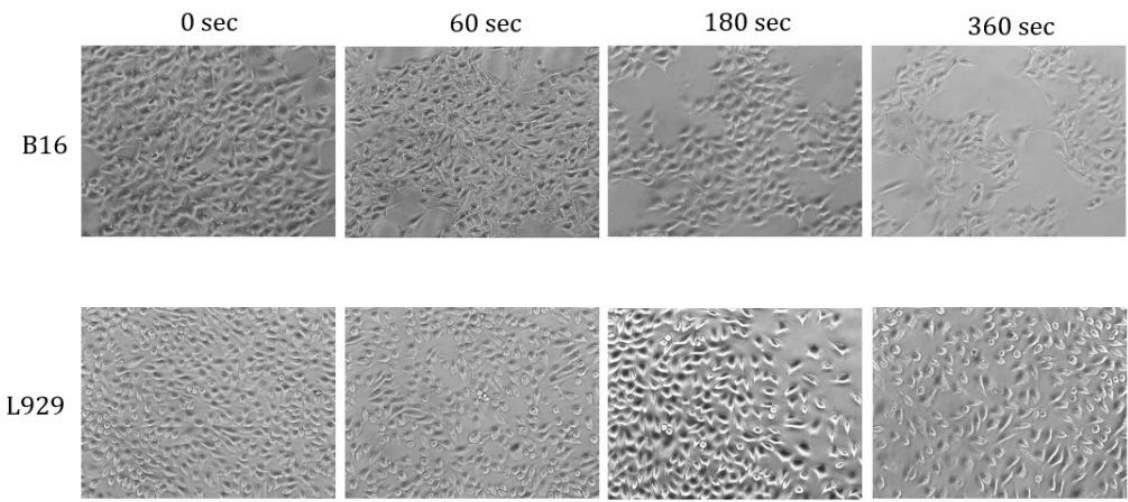

Figure 5. Images of attached cells with the same plasma treatment time durations. The upper row is B16 cells, and the bottom row is L929 cells.

Tumor metastasis occurs with a series of steps such as cell migration, adhesion, proliferation, invasion, and vessel formation, which is regulated by a complex mechanism. So, we investigated the effects of CAP treated medium on the melanoma cell migration behavior via a migration assay, as shown in Figure. 6 . The CAP treated medium in the migration assay model shows a negative effect on the melanoma cells' migration and gap closure. Longer treatment time shows a significant effect on gap closure and led to a significant closure delay. After $48 \mathrm{~h}$ incubation, more than $50 \%$ of the wound area is still open when the melanoma cells are under plasma treatment for 180 and $360 \mathrm{sec}$. The onset of gap closure is delayed until after $6 \mathrm{~h}$ for CAP treated melanoma cells, and the closure speed is lower compared with the untreated control group. These results indicate that CAP plasma treatment plays an important role in mediating the migration ability of melanoma cells.

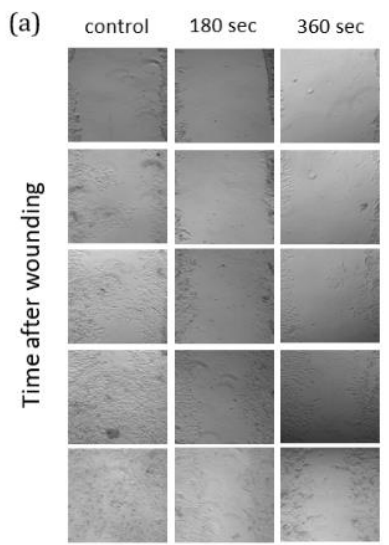

(b)

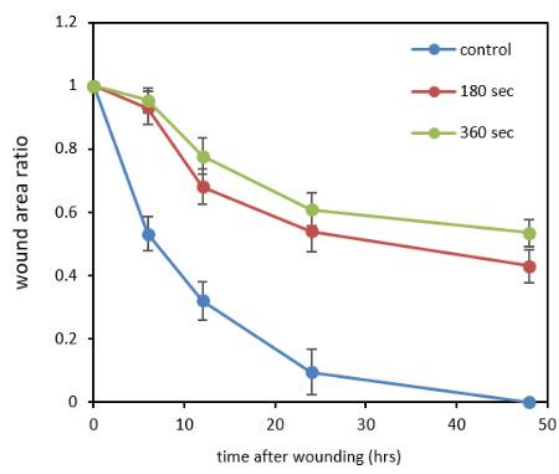

Figure 6. Effects of cold atmospheric plasma (CAP) on melanoma migration. (a) microphotographs of gap areas. (b) Quantitative results of migration assays. 
The CAP plasma can generate plenty of charged particles and free radicals, including reactive oxygen and nitrogen species. When the culture medium is treated with CAP plasma, the charged particles and free radicals can result in the generation of ROS in the culture medium. The ROS produced in the medium by CAP plasma can move across the cell membrane and interact with amino acid and protein to generate long-lived reactive hydroperoxides. The CAP plasma-induced ROS stress in cells will activate a series of apoptosis-related proteins then cause apoptotic cell death. Figure. 7 shows fluorescence images of ROS in B16 and L929 cells with different plasma treatment times. These images show that the content of ROS in B16 and L929 cells increases as the treatment time increases. The ROS content in B16 cells is much more than that in L929 cells with the same plasma treatment time. When ROS interacts with cells, the cellular antioxidant system will be activated to protect cells by activating antioxidative enzymes. The normal cells can bear more oxidative stress because they can neutralize ROS more efficiently. In contrast, the ROS concentration in tumor cells is higher, and the excessive oxidative stress will cause apoptotic cell death [26,27].

The Alizarin red, an anthraquinone dye, has been widely used to evaluate calcium deposits in cell culture. The intracellular or extracellular calcium deposition happens in dying or dead cells that are caused by apoptosis. Figure. 8 shows the Alizarin red staining results of B16 and L929 cells under different plasma treatment times, and the red stain represents the calcium deposits. These images show that the content of calcium deposits in B16 cells increases as the treatment time increases. The calcium deposits content in B16 cells is much more than that in L929 cells with the same plasma treatment time. When more ROS is exerted in cells, the B16 cells will experience more apoptosis and DNA damage than L929 cells under identical plasma exposure time and results in more calcium release and deposition intra or extra cells $[13,28]$.

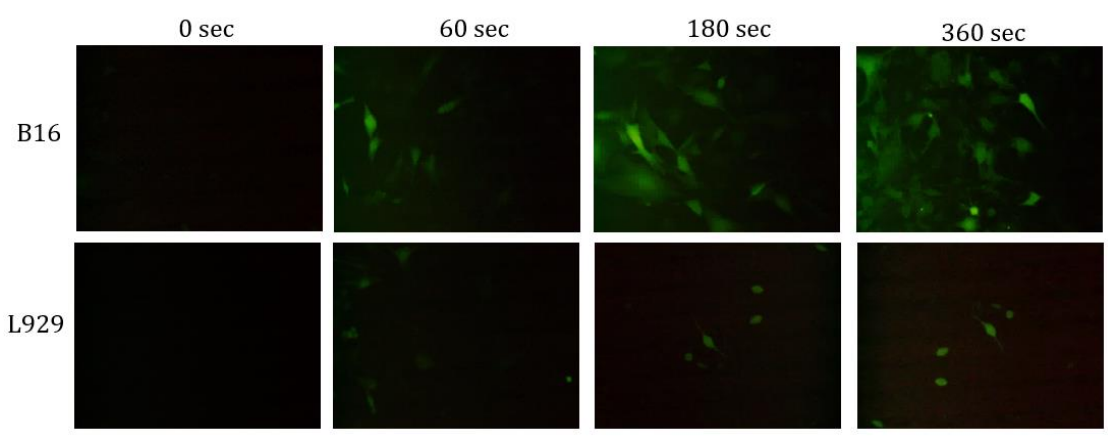

Figure 7. ROS content in cells. The fluorescent micrographs of B16 (upper row) and L929 cells (bottom row).

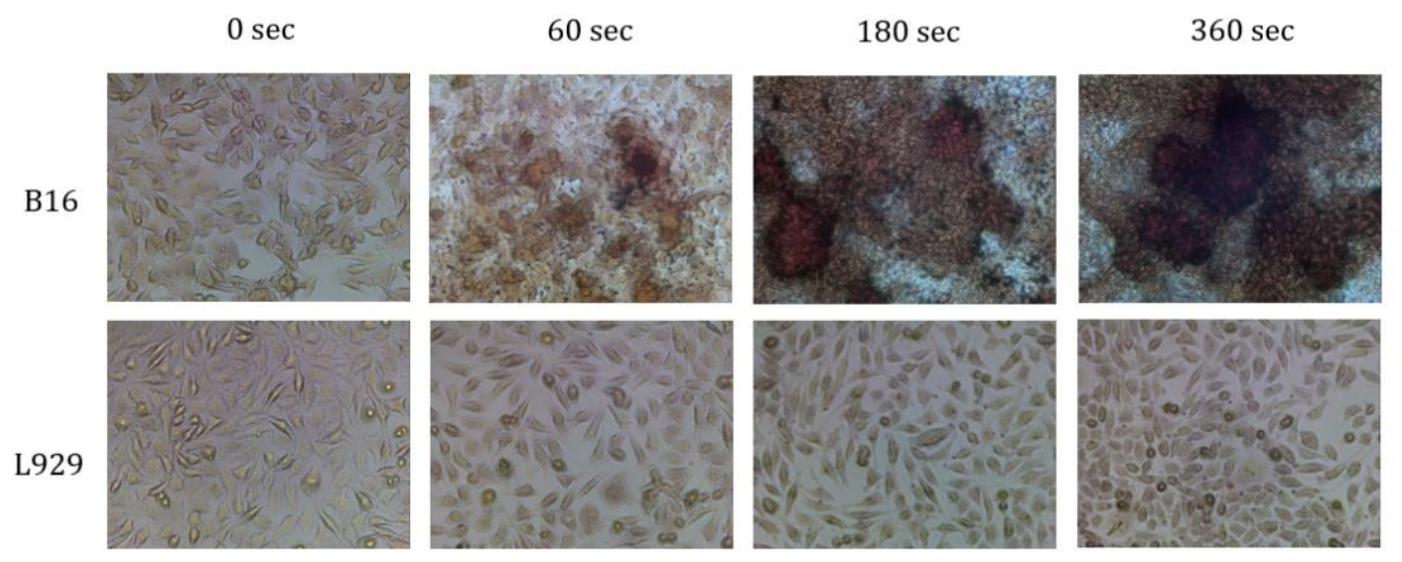

Figure 8. Alizarin red staining results of B16 (upper row) and L929 (bottom row)cells under different plasma treatment time. 


\section{Conclusions}

This paper presents a cold atmospheric pressure plasma jet device for the indirect treatment of melanoma B16 cells and fibroblast L929 cells. The cell assay results point out that CAP plasma-treated medium can significantly decrease cell viability and inhibit migration ability and induce apoptotic cell death for melanoma B16 cells. For fibroblast L929 cells, the plasma-treated medium has much less cytotoxic effect than that on melanoma B16 cells with identical plasma treatment. Significant amounts of ROS produced in CAP plasma-treated medium can be used as effective and selective treatment against melanoma cancer cells. These results demonstrate that indirect CAP treatment can selectively induce apoptotic cell death in melanoma cancer cells compared to normal fibroblast cells and show the potential for clinical cancer therapy.

\section{Funding}

This research received no external funding.

\section{Acknowledgments}

The authors are thankful to Dr. Ming-Chen Wang for the setup support of cold atmospheric pressure plasma jet device.

\section{Conflicts of Interest}

The authors declare no conflict of interest.

\section{References}

1. Sorensen, M.R.; Pedersen, S.R.; Lindkvist, A.; Christensen, J.P.; Thomsen, A.R. Quantification of B16 melanoma cells in lungs using triplex Q-PCR - a new approach to evaluate melanoma cell metastasis and tumor control. PLoS One 2014, 9, https://doi.org/10.1371/journal.pone.0087831.

2. Perillo, B.; Donato, M.D.; Pezone, A.; Zazzo, E.D.; Giovannelli, P.; Galasso, G.; Castoria, G.; Migliaccio, A. ROS in cancer therapy: the bright side of the moon. Exp. Mol. Med. 2020, 52, 192-203, https://doi.org/10.1038/s12276-020-0384-2

3. Liguoro, D.; Fattore, L.; Mancini, R.; Ciliberto G. Drug tolerance to target therapy in melanoma revealed at single cell level: What next?, Biochim Biophys Acta Rev Cancer. 2020, 1874, 188440, https://doi.org/10.1016/j.bbcan.2020.188440

4. Bai, X.; Fisher D.E.; Flaherty, K. Cell-state dynamics and therapeutic resistance in melanoma from the perspective of MITF and IFN $\gamma$ pathways. Nat. Rev. Clin. Oncol. 2019, 16, 549-562, https://doi.org/10.1038/s41571-019-0204-6

5. Orgaz, J.L.; Crosas-Molist, E.; Sadok, A.; Perdrix, A.; Maiques, O.; Rodriguez-Hernandez, I.; Monger, J.; Mele, S.; Georgouli, M.; Bridgeman, V.; Karagiannis, P.; Lee, R.; Pandya, P.; Boehme, L.; Wallberg, F.; Tape, C.; Karagiannis, S.N.; Malanchi, I.; Sanz-Moreno, V. Myosin II Reactivation and Cytoskeletal Remodeling as a Hallmark and a Vulnerability in Melanoma Therapy Resistance, Cancer Cell 2020, 37, 85103, https://doi.org/10.1016/j.ccell.2019.12.003.

6. Franke, J.C.; Plotz, M.; Prokop, A.; Geilen, C.C.; Schmalz, H.-G.; Eberle, J. New caspase-independent but ROS-dependent apoptosis pathways are targeted in melanoma cells by an iron-containing cytosine analogue. Biochem. Pharmacol. 2010, 79, 575-586, https://doi.org/10.1016/j.bcp.2009.09.022.

7. Li, X.; Fang, P.; Mai, J.; Choi, E.T.; Wang, H.; Yang, X.-F. Targeting mitochondrial reactive oxygen species as novel therapy for inflammatory diseases and cancers. J. Hematol. Oncol. 2013, 6, 19. https://doi.org/10.1186/1756-8722-6-19

8. Trachootham, D.; Alexandre, J.; Huang, P. Targeting cancer cells by ROS-mediated mechanisms: a radical therapeutic approach? Nat. Rev. Drug Discov. 2009, 8, 579-591, https://doi.org/10.1038/nrd2803.

9. Fridman, G.; Friedman, G.; Gutsol, A.; Shekhter, A.B.; Vasilets, V.N.; Fridman, A. Applied plasma medicine. Plasma Process Polym 2008, 5, 503-533, https://doi.org/10.1002/ppap.200700154. 
10. Kalghatgi, S.; Kelly, C.M.; Cerchar, E.; Torabi, B.; Alekseev, O.; Fridman, A.; Friedman, G. AzizkhanClifford, J. Effects of non-thermal plasma on mammalian cells. PLoS One 2011, 6, https://doi.org/10.1371/journal.pone.0016270.

11. Hoffmann, C.; Berganza, C.; Zhang, J. Cold atmospheric plasma: methods of production and application in dentistry and oncology. Medical Gas Res. 2013, 3, https://doi.org/10.1186/2045-9912-3-21.

12. Attri, P.; Arora, B.; Choi, E.H. Utility of plasma: a new road from physics to chemistry. RSC Adv. 2013, 3, 12540-12567, https://doi.org/10.1039/C3RA41277F.

13. Keidar, M. Plasma for cancer treatment. Plasma Sources Sci Technol 2015, 24, https://doi.org/10.1016/j.cpme.2013.08.001.

14. Balzer, J.; Demir, E.; Kogelheide, F.; Fuchs, P.C.; Stapelmann, K.; Opländer, C. Cold atmospheric plasma (CAP) differently affects migration and differentiation of keratinocytes via hydrogen peroxide and nitric oxide-related products. Clinical Plasma Medicine $2019, \quad 13, \quad 1-8$, https://doi.org/10.1016/j.cpme.2018.11.001.

15. Keidar, M.; Walk, R.; Shashurin, A.; Srinivasan, P.; Sandler, A.; Dasgupta, S.; Ravi, R.; Guerrero-Preston, R.; Trink, B. Cold plasma selectivity and the possibility of a paradigm shift in cancer therapy. Br. J. Cancer 2011, 105, 1295-1301, https://doi.org/10.1038/bjc.2011.386.

16. Kim, J.Y.; Ballato, J.; Foy, P.R.; Hawkins, T., Wei, Y., Li, J.; Kim, S. Apoptosis of lung carcinoma cells induced by a flexible optical fiber-based cold microplasma. Biosens. Bioelectron. 2011, 28, 333-338, https://doi.org/10.1016/j.bios.2011.07.039.

17. Asano, S.; Urabe, A.; Okabe, T.; Sato, N.; Kondo, Y. Demonstration of granulopoietic factor(s) in the plasma of nude mice transplanted with a human lung cancer and in thetumor tissue. Blood 1977, 49, 845-852, https://doi.org/10.1182/blood.V49.5.845.845.

18. Zhang, X.; Li, M.; Zhou, R.; Feng, K.; Yang, S. Ablation of liver cancer cells in vitro by a plasma needle. Appl. Phys. Lett. 2008, 93, https://doi.org/10.1063/1.2959735.

19. Walk, R. M.; Snyder, J.A.; Srinivasan, P.; Kirsch, J.; Diaz, S.O.; Blanco, F.C.; Shashurin, A.; Keidar, M.; Sandler, A.D. Cold atmospheric plasma for the ablative treatment of neuroblastoma. J. Pediatr. Surg. 2013, 48, 67-73, https://doi.org/10.1016/j.jpedsurg.2012.10.020.

20. Volotskova, O.; Hawley, T.S.; Stepp, M.A.; Keidar, M. Targeting the cancer cell cycle by cold atmospheric plasma. Sci. Rep. 2012, 2, https://doi.org/10.1038/srep00636.

21. Arndt, S.; Wacker, E.; Li, Y.F.; Shimizu, T.; Thomas, H.M.; Morfill, G.E.; Karrer, S.; Zimmermann, J.L.; Bosserhoff, A.K. Cold atmospheric plasma, a new strategy to induce senescence in melanoma cells. Exp. Dermatol. 2013, 22, 284-289, https://doi.org/10.1111/exd.12127.

22. Georgescu, N.; Lupu, A.R. Tumoral and normal cells treatment with high-voltage pulsed cold atmospheric plasma jets. IEEE Trans Plasma Sci 2010, 38, 1949-1955, https://doi.org/10.1109/TPS.2010.2041075.

23. Brullé, L.; Vandamme, M.; Riès, D.; Martel, E.; Robert, E.; Lerondel, S.; Trichet, V.; Richard, S.; Pouvesle, J.M.; Le Pape, A. Effects of a non thermal plasma treatment alone or in combination with gemcitabine in a MIA PaCa2-luc orthotopic pancreatic carcinoma model. PLoS One 2012, 7, https://doi.org/10.1371/journal.pone.0052653.

24. Ahn, H. J.; Kim, K.I.; Kim, G.; Moon, E.; Yang, S.S.; Lee, J.S. Atmospheric-pressure plasma jet induces apoptosis involving mitochondria via generation of free radicals. PLoS One 2011, 6, https://doi.org/10.1371/journal.pone.0028154.

25. Leduc, M.; Guay, D.; Leask, R.; Coulombe, S. Cell permeabilization using a non-thermal plasma. New J. Phys. 2009, 11, https://doi.org/10.1088/1367-2630/11/11/115021.

26. Fofana, M.; Buñay, J.; Judée, F.; Baron, S.; Menecier, S.; Nivoix, M.; Perisse, F.; Vacavant, A.; Balandraud, $\mathrm{X}$. Selective treatments of prostate tumor cells with a cold atmospheric plasma jet. Clinical Plasma Medicine 2020, 17-18, https://doi.org/10.1016/j.cpme.2020.100098.

27. Partecke, L. I.; Evert, K.; Haugk, J.; Doering, F.; Normann. L.; Diedrich, S.; Weiss, F.U.; Evert, M.; Huebner, N.O.; Guenther, C.; Heidecke, C.D.; Kramer, A.; Bussiahn, R.; Weltmann, K.D.; Pati, O.; Bender, C.; von Bernstorff, W. Tissue tolerable plasma (TTP) induces apoptosis in pancreatic cancer cells in vitro and in vivo. BMC Cancer 2012, 12, https://doi.org/10.1186/1471-2407-12-473.

28. Ishaq, M.M Bazaka, K.; Ostrikov, K. Intracellular effects of atmospheric-pressure plasmas on melanoma cancer cells. Phys Plasmas 2015, 22, https://doi.org/10.1063/1.4933366.

29. Graves, D.B. The emerging role of reactive oxygen and nitrogen species in redox biology and some implications for plasma applications to medicine and biology. J. Phys. D 2012, 45. 